\title{
Texto alternativo. \\ En camino a la \\ V Conferencia de Aparecida
}

\section{Profesores de la Facultad de Teología de la Compañía de Jesús, FAJE-ISI, Belo Horizonte, Brasil.}

La conferencia de Aparecida tendrá lugar dentro de un caminar que transcure desde el nacimiento del CELAM hasta al día de hoy, pasando por el concilio Vaticano II, Medellín, Puebla y Santo Domingo.

Es un momento privilegiado para un doble movimiento eclesial. Por una parte, para mirar al pasado y preguntarnos cuáles han sido las opciones que se han hecho, en ese caminar, las cuales juzgamos absolutamente innegociables y que nos gustaría reforzar. Por otra parte, para mirar al presente y al futuro, y formular las preguntas a las cuales la Iglesia debe prestar atención.

Aquí no seguiremos el texto del Documento de participación - presentando algunos añadidos -, sino que elaboraremos un texto altemativo con las contribuciones que juzgamos oportunas.

\section{Reafirmación de opciones}

\subsection{Opciones básicas del concilio Vaticano II}

Ningún acontecimiento eclesial de la importancia de la Conferencia de Aparecida puede ignorar las opciones básicas del concilio Vaticano II, como líneas obligatorias del caminar de la Iglesia, en el continente. Siendo el concilio una mina fecunda, para no abarcar demasiado y debilitar asl la acción de la Iglesia, nos contentamos con seleccionar algunas opciones conciliares, que juzgamos importantes y obligatorias.

Antes de mencionar dichas opciones, recordemos algo fundamental: en el concilio, la Iglesia sólo se entiende a partir de Jesús y su actitud fundamental. 
Movido por la pasión por el Padre, Jesús anuncia y realiza, a través de su persona, su predicación y su práctica, el reino de Dios, que consiste, fundamentalmente, en el servicio al mundo. "Pues el Hijo del hombre no vino a ser servido, sino a servir y a dar la vida en rescate por muchos" (Mt 10, 45). La Iglesia no existe, pues, para sí misma, sino para servir el mundo. En este espíritu jesuánico, hay que situar las opciones del concilio Vaticano $\amalg$.

\section{Primera: el primado absoluto de la Palabra de Dios}

En la práctica, esto significó una gran riqueza en muchos ámbitos eclesiales. Se revalorizó la palabra de Dios, en la liturgia, en las celebraciones y en todas las actividades religiosas. Ocupo su lugar debido en la producción teológica, en la formación del clero y en la vida de los creyentes. Se multiplicaron las obras de exégesis sobre temas bíblicos, que ofrecían ayudas al creyente para alimentarse espiritualmente de la Escritura.

\section{Segunda: la afirmación de la base laical de la Iglesia:} Iglesia pueblo de Dios

En la concepción de la Iglesia se dio una revolución copernicana. Al tratar de definirla, en lugar de partir de la jerarquía, el concilio afirmó el hecho fundamental: todos somos iguales por los sacramentos de iniciación y la participación en la eucaristía. La Iglesia fue definida como pueblo de Dios. En ella, los laicos encontraron su verdadero lugar, con amplios espacios de iniciativa, libertad, autonomía, participación, creación de espiritualidades propias.

Por lo que toca a América Latina, surgieron las primeras comunidades eclesiales de base, en estrecha conexión con la experiencia de los nuevos ministerios laicales. Estas comunidades crecieron con la dinámica que, después, generó Medellín. Y Pablo VI profundiz6, en los ministerios de no ordenados.

\section{Tercera: la afirmación coległal de la Iglesia}

En íntima relación con la base laical de la Iglesia, el Vaticano I generó un esplritu colegial, superando el modelo centralizado de Iglesia, que, antes del concilio, giraba alrededor de tres centros: Roma, la diócesis y la partoquia. La colegialidad supuso aire nuevo. Se pudo respirar, en el ámbito de toda la Iglesia, pues revalorizó la Iglesia local y las comunidades. Con el crecimiento de las conferencias episcopales, los consejos diocesanos, parroquiales y comunitarios, se cré 6 una conciencia de sinodalidad y de comunión,

\section{Cuarta: la nueva relación de la Iglesia con el mundo}

La constitucion Gaudium et spes proclamó la intima sintonía de los cristianos con los hombres y las mujeres del mundo de hoy, en sus alegrías y 
esperanzas, en sus tristezas y angustias. Hizo que cambiara la actitud de la Iglesia ante los problemas fundamentales del mundo moderno. Reconoció la autonomía de las realidades temporales y terrestres, y renunció a los últimos vestigios de cristiandad. Asumió el pluralismo de la modemidad, y superó la tentación de reprender al mundo o de mantenerse en actitud de dominio, en lugar del servicio al mundo.

\subsection{Opciones básicas de Medellín}

En Medellín, la Iglesia de América Latina llevó a cabo una "recepción" creativa del concilio Vaticano II, y tomó importantes decisiones. Algunas pensamos que son irrenunciables, y ya forman parte de la sana y legítima tradición eclesial, que debe ser mantenida y reforzada en Aparecida.

\section{Primera: la opción por los pobres}

La herencia más sagrada de Medellín es la opción por los pobres, directa, clara, sin adjetivos. Esta opción configura los diferentes campos de la vida interna y externa de la Iglesia: personas, pastorales, estructurales. Nada en la vida de la Iglesia puede sustraerse a esa opción básica. Se hizo presente en la conversión de miembros de la jerarquía, de religiosos y religiosas, de agentes de pastoral y de simples creyentes.

\section{Seguna: la opción por la liberación}

Se articulo con la opción por los pobres, sin identificarse del todo con ella. Consistio, en lo fundamental, en orientar la opción por los pobres, en la línea de su promoción humana, a saber, la liberación integral, en el lenguaje de Pablo VI (Populorum progressio). "Liberación" se transformó también en categoría teol6gica, al incluir la transformación de sentido. El concepto provenía de las ciencias políticas y se amplió histórica y antropológicamente, hasta convertirse en categoría fundamental de la teología de la liberación.

Tercera: la opción por las comunidades eclesiales de base

La opción por los pobres y por la liberación encontró en las comunidades eclesiales de base una "nueva manera de ser Iglesia". Surgieron antes que Medellín, pero en Medellín recibieron aval institucional, ánimo y una mejor configuracion.

\section{Cuarta: la opción por la centralidad de la justicia social}

Es consistente con las opciones anteriores. Super6 las antiguas posiciones tradicionales asistencialistas e hizo que el pensamiento teológico y la pastoral despertaran a la realidad de la injusticia social, del pecado social. Condena la 
violencia institucional del propio sistema y no únicamente la de las guemillas y la de la lucha armada.

\section{Quinta: la opción por una Iglesia profética}

El conjunto de opciones de Medellín configuró una Iglesia profética, en el discurso, en la teología, en las prácticas y en las estructuras institucionales. Rompió la alianza con la burguesía para denunciar la secular dominación que ésta siempre ha ejercido, y para anunciar una sociedad solidaria, fraterna, participativa, igualitaria.

\subsection{Opciones básicas de Puebla}

En Puebla, la situación política eclesial había cambiado notablemente. No se consiguió la misma claridad y precisión que en Medellín. En la práctica, sin embargo, algunas opciones fueron confirmadas, y otras han quedado como una herencia, que debe ser mantenida.

\section{Primera: la opción por los pobres}

En un ambiente de cierta tensión en el interior de la Iglesia, y con las fuerzas conservadoras dominando la sociedad, se reafirmó la opción por los pobres, pero adjetivándola para evitar conflictos. Sin embargo, se mantuvo el núcleo de esa opción, en un contexto que era complejo y perplejo.

\section{Segunda: la opción por los jovenes}

Más allá de cualquier interés estratégico, la opción por los jovenes hizo que se prestase atención a este grave problema. Después de la crisis y desaparición, especialmente de la Juventud Estudiantil Católica (JEC) y de la Juventud Universitaria Católica (JUC), la pastoral de jóvenes trató de sobrevivir en tiempos de incertidumbre, tanteos y búsqueda. Puebla animó a la nueva búsqueda de formas de pastoral juvenil.

\section{Tercera: la opción por la comunión y participación}

Anticipándose, en cierto modo, al Sínodo de 1985, que consideró la "comunión" como clave central interpretativa de la eclesiología del concilio Vaticano II, Puebla comprendió la Iglesia a partir de la "comunión y participación". Esa opción se articula con las comunidades eclesiales de base, como "nuevo modo de ser Iglesia", en las que se manifiesta y se concretiza con mayor claridad la comunión y participación.

\section{Cuarta: la opción por la defensa de la dignidad de la persona humana}

En momentos de represión, por parte de los gobiemos militares en América Latina, Puebla asumió la postura profética de denuncia y anuncio, al defender la 
dignidad de la persona, ante las violaciones cometidas por los regímenes militares. Esa actitud audaz se convirtió en "seña" de la Iglesia de América Latina, en presencia de la represión y de la arbitrariedad.

\subsection{Opciones básicas de Santo Domingo}

En un nuevo contexto de apertura política, contrastante con el anterior, pero bajo el imperio inflexible del neoliberalismo, y en una situación eclesial ya claramente centralizadora, Santo Domingo percibió nuevos desafíos, que fueron objeto de varias opciones.

\section{Primera: la opción por la inculturación}

Uno de los puntos novedosos e importantes de Santo Domingo consistió en tomar una mayor conciencia de la relevancia de las culturas amerindia, afro y de la religiosidad popular como espacio de la evangelización, con el consecuente avance en el tema de la inculturación. Afirmó la pluralidad de expresiones de fe, inculturadas en la realidad urbana y en las culturas afro-amerindias, y asumió la religión del pueblo de forma positiva.

\section{Segunda: la opción por el protagonismo del laico}

Es marca registrada de Santo Domingo. Por un lado, el desarrollo de la nueva teología del laicado, debido al crecimiento de las comunidades eclesiales de base, y por otro, la dramática situación de una Iglesia con escasez de ministros ordenados, llevó a los obispos a la opción por el protagonismo del laico.

\section{Tercera: la opción por una sociedad a la vez latinoamericana y mundial}

La paradójica realidad de la globalización y la necesidad de afirmar las identidades regionales exigió de la Iglesia una mayor conciencia frente a la construcción de la solidaridad continental, en defensa de los pobres y de las culturas autóctonas. Dicho esto, se percibió la importancia de alianzas más amplias, en dimensión mundial, para el anuncio de los valores del reino de Dios.

\section{Cuarta: la opción por la lectura de la realidad, a partir de los "signos de los tiempos"}

Santo Domingo volvió a una lectura de la realidad, a partir de "los signos de los tiempos". Es una herencia de la tradición teológica de la liberación, que se inspiró en la enseñanza social de Juan XXIII y en la constitución pastoral Gaudium et spes. 


\section{El avance a nuevos temas y decisiones}

Reafirmar las opciones anteriores ya es una tarea ingente. Pero la historia sigue su marcha y la Iglesia necesita responder a los nuevos desafíos. Señalemos algunos.

\subsection{Animación "carismática" de las estructuras internas de la Iglesia}

El fenómeno carismático existe con gigantesco vigor en el continente. ¿Cómo no percibir en ello una señal del Espíritu? Como toda acción de Dios en la historia, está transido de ambigliedad, y además, carece de discemimiento. Y nunca hay que olvidar que todo cristiano, por la gracia del bautismo, es un carismático, y ningún movimiento tiene el derecho de revindicar el privilegio de poseer en exclusiva el Espíritu Santo.

El dinamismo carismático posee un inmenso potencial transformador de las instituciones, si en él se hace real el principio jesuánico de que "el sábado es para el hombre y no el hombre para el sábado". En otras palabras, le es propia la maravillosa tarea de humanizar - en el pleno sentido del término - la rigidez de muchas formas institucionales y jurídicas de la Iglesia. Esto supone revigorizar la dimensión de diaconía, de pobreza, de simplicidad en el ser, en el vestir y en el vivir de los representantes de la Institución eclesiástica.

Los movimientos carismáticos adoptan, a veces, posiciones antitéticas. Unos están fuertemente centralizados en la persona del líder, lo que no ayuda a liberar a la Iglesia de formas centralizadoras y autoritarias. Otros, por el contrario, cultivan una libertad transparente entre sus miembros. Estos están en condiciones de pensar y ensayar un modelo "democrático" y participativo de Iglesia. Y si se articulan con las comunidades eclesiales de base, anticipan ya una Iglesia, red de comunidades, en el interior de las parroquias y diocesis. Entonces, para el creyente, la Iglesia se convierte en una comunidad de libertad, de diálogo, de acogida y de igualdad. Y este mismo espíritu, facilita que el gobiemo de la Iglesia actúe según el principio de subsidiariedad.

La preocupación pastoral por el éxodo de católicos y por la multiplicación de las denominaciones evangélicas, en el seno del fenómeno religioso, hace urgente repensar en profundidad el ministerio, en la Iglesia católica. Esto implica una reformulación del ministerio ordenado, en la linea del servicio, despojado de autoritarismo y centralismo pastoral. Lleva a repensar cómo reinsertar en el ministerio ordenado a aquellos que lo abandonaron, y que estarían dispuestos a regresar, en una nueva situación. Finalmente, lleva a una actitud audaz, innovadora, ante las posibilidades ministeriales de las mujeres. 


\subsection{Evangèlización de una nueva sociedad - globalizada - del cono- cimiento}

Cada día avanzan más las ciencias y la alta tecnologla, en especial, en el campo de las ciencias de la vida y de la información, lo que trae consigo graves problemas éticos. El conocimiento llega a ser la materia prima, sumamente importante en el mundo de la producción y de la gerencia de las empresas. Fuera del conocimiento no hay competitividad.

La Iglesia necesita de laicos y laicas, de profesores y profesoras de ética y de teología moral, preparados para tal diálogo. Un laicado valiente y competente, apoyado por el magisterio, ahorraría a la Iglesia declaraciones oficiales desafortunadas y $\sin$ suficientes conocimientos sobre temas que son difíciles, complejos y aun oscuros.

La sociedad del conocimiento generará un nuevo tipo de pobres y de excluidos. El desafío para la Iglesia es descubrir sus rostros concretos y reales, como lo hizo en Puebla (nn. 31-39). Eso significa ir más allá de la opción por los pobres de Medellín y Puebla, liberándola de epítetos ideológicos, que la debilitan, para recuperar la fuerza evangélica. En una palabra, estamos ante la tarea de retomar con amplitud la práctica de la liberación, en el contexto neoliberal.

\section{Evangelización de la cultura moderna y posmoderna}

Es ya impensable una evangelización que no tenga en cuenta la cultura. El fracaso del socialismo real se debió, además de los fallos económicos, a no haber creado, culturalmente, al hombre nuevo deseado. Se descuido la cultura.

La presencia de la Iglesia en la sociedad futura depende de cómo se situé en el campo cultural. No puede hacerlo como adaptación cultural a los valores burgueses capitalistas, sino como construcción de una cultura, a partir de los pobres. El socialismo creó el imaginario de la liberación, pero fracasó, debido a la ausencia de valores fundamentales. La Iglesia está en condiciones de introducir en el imaginario liberador social rasgos evangélicos, que otorgan consistencia y profundidad a aquél. La evangelización de la cultura actual, moderna y posmoderna, exige construir en el interior de la Iglesia, y por medio de la pastoral, de discursos, prácticas, instancias y símbolos también fuera de ella, un imaginario que exprese la opción por la liberación de los pobres. Sólo así se consigue transformar la realidad.

En otros términos, esto significa la creación de un nuevo paradigma cultural, como verdadera altemativa al pensar único dominante, que tenga en consideración las mejores conquistas del momento actual: el pensar ecológico, la cosmología moderna, el género, las etnias, la paz, la ética del cuido y de la compasión. 


\subsection{Un desarrollo eficaz de la pastoral de los inmigrantes}

Las migraciones se han convertido en un fenómeno creciente en todo el mundo y en el interior de los paises, que desafían la pastoral de la Iglesia. Ya son centenares de millones las personas que, en migraciones crecientes, se mueven al interior de los países y hacia fuera de ellos. ¿Por qué abandonan la propia tierra? ¿Por qué buscan otra tierra y cuál es la que buscan? Hay factores de expulsión y de atracción. Desde lo objetivo, nos encontramos con la pobreza, la falta de futuro allá dónde uno vive, la creciente discriminación económica, racial y religiosa, los conflictos internos regionales. Desde lo subjetivo, deslumbran los sueños de riqueza de Estados Unidos, de dinero fácil y abundante, los anhelos de conseguir recursos rápidos para resolver definitivamente problemas, como el de la vivienda, y otras exigencias básicas. Pobreza y sueños, falta de futuro e ilusión de un futuro radiante, son las carencias del ser humano, que fray Beto llamó "hambre de pan y de belleza".

La pastoral del futuro tendrá que abordar varios problemas: desde la defensa de los derechos fundamentales del emigrante, sobre todo de los indocumentados, hasta una emigración del clero y de los religiosos. En la medida en que caminemos con lentitud o nos durmamos, las denominaciones evangélicas pentecostales y neopentecostales ocuparán rápidamente los espacios. Y no siempre para el bien de las personas. Al mencionarlo, no nos mueven razones proselitistas, sino sólo la lealtad evangélica y el amor hacia aquellos presa fácil de distorsiones religiosas.

\subsection{Invertir seriamente en una pastoral de los medios}

La ciencia y la tecnologla de la comunicación atraviesan una revolución nunca vista. Se anuncian gigantescos avances tecnológicos, que revolucionarán la relación entre las personas y crearán una nueva generación de usuarios.

Los desafíos pastorales consisten, entre otros, en la presencia significativa de la Iglesia, en el universo tecnologico y cultural, y en la articulación de tales medios con las exigencias comunitarias de la vida cristiana, con la disciplina del arcanum y con las características propias de la fe cristiana.

Los medios han llegado a ser mucho más que meros instrumentos de comunicación. Configuran la cultura actual. Un lenguaje teológico que no tuviese en cuenta ese dato cultural sería simplemente ignorado por los oyentes y los lectores. Como se trata de cultura, el empeño tiene que ser mucho mayor y en profundidad. Tiene que percibir los cambios en el comportamiento y en el horizonte simbólico de las personas. Sólo dentro de ese mundo se podrá evangelizar.

La cuestión es grave. Se trata de que una Iglesia real, comunitaria, pueda ser sustituida por una Iglesia virtual, lo cual puede ocurrir por causa de una pastoral mediática, nada lúcida, que sustituya la vida concreta eclesial. 


\subsection{Diálogo ecuménico e interreligioso}

En espiritu de apertura y tolerancia, señal decisiva de la cultura actual, y en las huellas del concilio Vaticano $\square$, se imponen decisiones audaces, en el campo ecuménico y del diálogo interreligioso, venciendo las luchas reñidas, que han minado incluso el interior de las familias. De la postura correcta ante tales cuestiones depende incluso la paz entre las personas, las etnias, las religiones y los países. "No hay paz mundial, sin paz entre las religiones" (Hans Küng).

\section{Conclusión}

En este momento de preparación para Aparecida, nos parece importante clarificar las opciones básicas innegociables e indeclinables de la herencia del concilio Vaticano II y de las conferencias anteriores, y asumir los nuevos desaflos. A esa doble tarea apuntan los elementos que aquí hemos indicado, en forma sucinta,

Mayo de 2006. 